\title{
DOCÊNCIA ORIENTADA EM TEMPOS DE PANDEMIA: DESAFIOS E POSSIBILIDADES
}

\author{
Alan Maciel Guterres ${ }^{1}$; Eliane Aparecida Galvão dos Santos²
}

\section{RESUMO}

Este trabalho é o resultado das experiências vivenciadas na disciplina de docência orientada no Curso de Mestrado em Ensino de Humanidades e Linguagens da Universidade Franciscana. Caracteriza-se como um estudo de abordagem qualitativa do tipo bibliografica e relato de experiência, sendo que a fundamentação teórica está sustentada por autores, que discutem sobre a docência no ensino superior. A Docência Orientada tem como objetivo contribuir para que o mestrando tenha uma vivência no ensino superior, mais especialmente no curso de graduação. Também, contempla estudos sobre a Pedagogia Universitária, fazendo a relação da teoria estudada nos encontros da disciplina no mestrado, com a prática da sala de aula na graduação.

Palavras-chave: Docência Orientada; Ensino Superior; Práticas Pedagógicas.

Eixo Temático: Educação, Cultura e Comunicação (ECC)

\section{INTRODUÇÃO}

Estamos vivendo uma realidade extremamente atípica, que não estávamos preparados para tal situação. Tudo isso tem nos desafiado constantemente a rever nossas posturas, crenças, valores e paradigmas. Esse novo cenário ocasionado pela pandemia do COVID-19, que instalou-se em nossas vidas, sobretudo na área educacional, nos traz enormes desafios.

Nesse sentido, é que se propõe a seguinte problemática: quais são os desafios e as possibilidades na realização da disciplina de docência orientada em

\footnotetext{
${ }^{1}$ Mestrando em Ensino de Humanidades e Linguagens - Universidade Franciscana -UFN. e-mail: alan.guterres79@gmail.com.

2 Doutora. Professora do Curso de Pedagogia e do Mestrado em Ensino de Humanidades e

Linguagens - Universidade Franciscana - UFN. e-mail: elianeagalvao1@gmail.com
} 


\section{QUFN}

tempos de pandemia? A partir disto, pretende-se responder à problemática fundamentando em autores que discorrem sobre o tema pesquisado, como também dos resultados alcançados a partir das vivências do autor como docente orientado no ensino superior na disciplina de Seminário Integrado V: Modalidades de Ensino e Diversidades sendo essa, uma disciplina compartilhada entre os cursos de licenciaturas da Universidade Franciscana, no município de Santa Maria/RS, com carga horária total de 40 horas, oferecida no $5^{\circ}$ semestre dos cursos. O docente orientado ministrou aulas com o acompanhamento do professor responsável pela disciplina totalizando 8 encontros de 2 horas semanais.

\section{METODOLOGIA}

Esta pesquisa é de abordagem qualitativa do tipo bibliográfica, que, segundo Gil (2002) é um tipo de pesquisa "desenvolvida com base em material já elaborado, constituído principalmente de livros e artigos científicos." (p. 44) e relato das experiências vivenciadas pelo autor, na disciplina de Docência Orientada, a partir de discussões embasadas em autores que discorrem sobre a docência no ensino superior, fazendo relações entre a teoria e a prática. Chizzotti (2018), destaca que:

\footnotetext{
A pesquisa qualitativa é uma designação que abriga correntes de pesquisa muito diferentes. Em síntese, essas correntes se fundamentam em alguns pressupostos contrários ao modelo experimental e adotam métodos e técnicas de pesquisa diferentes dos estudos experimentais.

Os cientistas que partilham da abordagem qualitativa em pesquisa se opõem, em geral, ao pressuposto experimental que defende um padrão único de pesquisa para todas as ciências, calcado no modelo de estudo das ciências da natureza. (p.78)
}

Como ponto central de discussão propõe-se a seguinte questão: "quais são os desafios e as possibilidades na realização da disciplina de docência orientada em tempos de pandemia? Dessa forma, buscou-se explicitar aspectos relacionados a formação de professores, através da influência da docência orientada, pois defende-se que este é um diferencial na trajetória formativa dos mestrandos. 


\title{
3. RESULTADOS E DISCUSSÕES
}

\subsection{Formação docente no processo pandêmico}

A formação de professores tem sido alvo de muitos estudos, questionamentos e, principalmente muitas pesquisas, por parte de estudiosos do assunto. Não é à toa que esse tema tem sido inúmeras vezes discutido em larga escala, dado a sua complexidade no contexto formativo.

Discutir o processo formativo, sobretudo, a formação inicial, a formação de outros professores, é, sem dúvida uma urgência nos nossos dias, sobretudo, frente às novas realidades que se descortinam a cada dia, ou seja, numa pósmodernidade onde tudo é passageiro, descartável, as coisas se transformam numa velocidade gigantesca; a essa realidade da qual estamos vivendo, Bauman chama modernidade líquida, conforme afirma Almeida (2009):

\begin{abstract}
Bauman comprende que, com a passagem da modernidade sólida à modernidade líquida, tanto a ordem imutável do mundo como a ordem não menos eterna da "natureza humana", princípios primordiais associados à tarefa educativa, se encontram em apuros. Eram esses pressupostos que garantiam, por um lado, os benefícios da transmissão do conhecimento aos alunos, e, de outro lado, forneciam ao professor a autoconfiança necessária para "gravar" na cabeça daqueles "[...] a forma que presumia ser, para todo o sempre, justa, bela e boa." ( p.65)
\end{abstract}

As realidades hoje se transformam a cada segundo. Nessa esteira de transformações tem-se imbricadas as transformações e mudanças no que diz respeito à formação dos professores, sobretudo para atuar no ensino superior.

Discutir sobre a formação inicial no ensino superior requer, primeiramente uma mudança de paradigmas, pois, como foi dito anteriormente as realidades se modificaram e estão se modificando a cada instante. Desta forma, o ensino superior requer um olhar mais pormenorizado, no que diz respeito à formação dos futuros professores, como também dos formadores, ou seja, dos professores que formam novos professores.

Para isso, faz-se necessário, discutir a forma como os professores formadores ministram suas aulas, como formam novos professores para atender às demandas de uma sociedade pós-moderna, que se ressignifica a cada segundo. Nesse sentido, cabe ressaltar que muitos professores universitários, em muitos casos, ainda desenvolvem suas práticas centradas na transmissão do 
conhecimento, conforme aprenderam quando estavam na universidade. Quando isso acontece, o processo de transmissão do conhecimento, de rigorosidade, de engessamento da forma como a aula é ministrada no ensino superior acaba distanciando a relação entre o aluno, o professor e o processo de construção do conhecimento. Nesse sentido, Lima e Grillo (2008) destacam que:

[...] Por essa razão, tendem a fundamentar sua prática pedagógica em modelos de professores que tiveram durante o período escolar ou em sugestões dadas por colegas mais experientes ou, ainda, na representação do professor, difundida na sociedade ocidental. Os docentes organizam o seu trabalho usando como referencial o "senso comum pedagógico", segundo o qual o domínio de uma área específica do saber, veiculado nos conteúdos escolares é condição para ser professor, ou ainda, que os conteúdos de ensino articulados a procedimentos ensinados pela Didática (as famosas técnicas) possibilitam ao docente dar conta da complexidade e das exigências do cotidiano da aula universitária, assegurando um desempenho eficiente. (p.22)

Diante do vivido nos dias atuais, em que depara-se com diversas problematizações, que são desafiadoras e, por isso, requerem que as práticas pedagógicas cotidianas sejam repensadas, com a necessidade de se lançar um olhar para o que é trabalhado em sala de aula, de forma especial, na universidade.

A formação para o docente atuar no ensino superior se faz por meio de cursos de mestrado e doutorado. Entretanto, esses, estão centrados na pesquisa, carecendo assim de espaços e tempos de formação que possibilite a apropriação de conhecimentos pedagógicos e saberes necessários à complexidade do que envolve a atividade docente no ensino superior. Segundo Lucarelli, (2000, p. 36)

A pedagogia universitária é um campo polissêmico de produção e aplicação dos conhecimentos pedagógicos na educação superior. Reconhece distintos campos científicos dos quais toma referentes epistemológicos e culturais para definir suas bases e características. A pedagogia universitária é, também, um espaço de conexão de conhecimentos, subjetividades e culturas, que exige um conteúdo científico, tecnológico ou artístico altamente especializado e orientado para a formação de uma profissão

A pandemia do COVID-19, veio para imprimir ainda mais a complexidade desse processo, pois fez-se necessário uma nova adaptação à forma como as aulas eram ministradas, assim como o acesso dos alunos às salas de aula na 
academia. Essas adaptações e mudanças requerem que as universidades reorganizem seus Planos de Ensino, adotem plataformas digitais para que os alunos possam assistir as aulas e interagirem, ainda que virtualmente, com os professores e os demais colegas, além disso, os professores necessitaram aprender repentinamente a utilizar as mais variadas ferramentas tecnológicas, além de ressignificarem sua metodologia e propostas de trabalho, adequando-as à nova realidade que se apresenta atualmente.

Essas novas mudanças e transformações que está se vivenciando são decorrentes da pós-modernidade, que se instalou na vida, na cultura, na sociedade e que requer uma inovação tanto tecnológica, quanto social, cultural e, principalmente educacional. Nesse sentido, Masetto (2012) destaca que:

\begin{abstract}
Marcamos como pressuposto que as inovações educacionais nunca se apresentam com a característica da neutralidade. Pelo contrário, sempre surgem como resultado de um contexto social, de determinada concepção de educação e como resposta a necessidades emergentes para as quais os paradigmas atuais não oferecem encaminhamentos aceitáveis. A inovação sempre emerge em um processo histórico de uma instituição, em determinado tempo, e ela mesma tem sua história, pois é um processo e não se esgota em medidas pontuais. (p. 16-17)
\end{abstract}

A inovação no ensino universitário visa romper com a fragmentação do conhecimento, romper com os paradigmas que estão cristalizados a muito tempo e que precisam ser ressignificados, como também, muda o foco do processo de ensino centrada no professor, passando ao aluno como protagonista de sua aprendizagem, como sujeito do processo. Nesse sentido, os professores são desafiados a promover um ensino em que as aprendizagens acontecem através das problematizações e discussões a respeito dos conteúdos a serem desenvolvidos, fazendo uma relação destes, com a realidade da qual o aluno está vivenciando.

Com a eclosão da pandemia do COVID-19, novos paradigmas precisaram ser rompidos, principalmente no que tange ao uso das tecnologias, pois as aulas que eram totalmente presenciais, passaram a ser totalmente remotas, mediadas por plataformas de aderência tecnológicas. 
As mudanças na forma de conduzir as aulas, no processo pandêmico sofreram mudanças significativas e foram regulamentadas e orientadas a partir da Portaria $n^{\circ} 343$, de 17 de março de 2020, sobretudo no Artigo 1ํㅜ , que afirma:

Autorizar em caráter excepcional, a substituição das disciplinas presenciais em andamento por aulas que utilizem meios e tecnologias de informação e comunicação nos limites estabelecidos pela legislação em vigor dos sistema federal de ensino [...] (BRASIL, 2020)

Essas novas ferramentas que passaram a ser utilizadas por professores e alunos para fazer aula, foram agregados aos planejamentos e propostas de ensino dos professores e das instituições de ensino, exigindo de todos os envolvidos no processo educativo (professores, alunos e instituição universitária), formação específica para que essas ferramentas fossem utilizadas na condução dos processos educativos.

A partir dessas realidades que se descortinam, assim como as demandas educativas se apresentam cada vez mais desafiadoras e complexas, os saberes adquiridos pelos docentes carecem de uma ressignificação, pois esses saberes fazem parte da prática docente e estão incorporados às práticas dos docentes, conforme afirma Tardiff (2014):

Os saberes sociais transformados em saberes escolares através dos saberes disciplinares e dos saberes curriculares, os saberes oriundos das ciências da educação, os saberes pedagógicos e os saberes experenciais. Em suma, o professor ideal é alguém que deve conhecer sua matéria, sua disciplina e seu programa, além de possuir certos conhecimentos relativos às ciências e à pedagogia e desenvolver um saber prático baseado em sua experiência cotidiana com os alunos. (p.39)

Diante do exposto acima, os saberes que os saberes que os professores trazem consigo, assim como os que foram adquiridos na sua formação inicial, e os construídos ao longo da sua trajetória como docente devem ter uma relação com a sua prática em sala de aula, oportunizando, a partir dessa relação um processo dialógico e reflexivo, acerca dos processos e paradigmas que estão vigentes atualmente, e que precisam ser assumidos pelos docentes, tendo em vista a construção do conhecimento por parte dos alunos. 


\section{RESULTADOS}

As práticas na disciplina de Seminário Integrador $V$ aconteceram de forma online, com aulas síncronas e assíncronas, através das plataformas digitais, teams e google meet.

Tendo em vista o processo pandêmico da qual se vive, fez-se necessário um planejamento diferenciado para as aulas tanto na disciplina de Docência Orientada, como nas práticas da pedagogia universitária.

Esse planejamento, como também o desenvolvimento das aulas buscaram integrar o uso das plataformas tecnológicas disponibilizadas pela instituição, para que as aulas pudessem acontecer, sem prejuízos acadêmicos ao alunos e ao ano letivo em curso.

Todos esses novos meios e processos que foram utilizados para ministrar as aulas, como também o planejamento que foi desenvolvido para atender a essa nova realidade, provocou uma inovação na forma como o ensino na universidade é ministrado e concebido, conforme afirma Masetto (2012):

Assim denomina-se inovação as novidades da era tecnológica da informação e da comunicação, as novas condições para o conhecimento, o interesse em superar a fragmentação nos diversos campos do conhecimento, a busca de um saber interdisciplinar, as recentes revisões das carreiras e dos perfis dos profissionais, até as demandas que o século XXI dirige à educação em seus diferentes ângulos. (p.22).

A inovação, nesse sentido, tem como premissas superar a fragmentação do conhecimento e promover a autonomia dos estudantes. Nesse sentido, as aulas que foram ministradas, foram conduzidas por esse viés, ou seja, proporcionar aos estudantes, tanto do mestrado, como também nas suas práticas, e aos alunos da graduação o desenvolvimento de sua autonomia, no que diz respeito ao planejamento e apresentação de seus trabalhos que foram propostos. Essa nova forma de organização, de apresentação, faz com que o aluno se torne protagonista de sua própria aprendizagem, ressignificando os conhecimentos já obtidos, fazendo uma relação estreita com a realidade da qual ele vivencia. 
Para que a realização das práticas fossem possíveis, o mestrando participou das aulas na disciplina de docência orientada, que, a partir do estudo de diversos autores que discutiram a respeito da pedagogia universitária, tornou-se possível o aprofundamento e a fundamentação teórica para a atuação do aluno frente à turma de graduação de Seminário V: Modalidades de Ensino e Diversidades.

Com esse aporte teórico-metodológico, foi possível ao mestrando, em contato com a Professora da disciplina e também com a professora titular da turma de graduação desenvolver um planejamento das intervenções que mobilizassem os graduandos serem protagonistas de seu próprio conhecimento.

As aulas foram planejadas na forma de seminário, onde cada grupo de alunos ficou responsável por pesquisar e estudar as diferentes modalidades de ensino ${ }^{3}$. A partir desses estudos, foi promovida a discussão no grande grupo, que com a mediação e orientação do mestrando e da professora da turma, contribuíram na problematização e na complementação dos temas discutidos. A escolha dos temas pelos grupos levou em conta o interesse pelo tema a ser pesquisado e, também, a realidade vivenciada por muitos graduandos, frente aos temas abordados.

Para tornar as aulas da graduação ainda mais inovadoras e interessantes, foi oferecido aos graduandos uma palestra com uma pesquisadora da Universidade Federal de Santa Maria, abordando o tema: educação quilombola e diversidade cultural na formação de professores, onde foram discutidos vários pontos importantes a respeito dessa modalidade de ensino, bem como, sobre a cultura, o currículo, a legislação e a formação dos docentes para atuarem junto às comunidades quilombolas, proporcionando momentos valiosos de discussão e problematização acerca do tema abordado.

A prática desenvolvida pelo mestrando na turma de graduação veio ao encontro de toda a teorização e fundamentação estudada na disciplina de docência orientada, fazendo a relação desses conhecimentos construídos durante as aulas, com as práticas desenvolvidas junto aos alunos, e que a construção e a problematização do conhecimento são de fundamental importância para promover a

\footnotetext{
${ }^{3}$ Educação de Jovens e Adultos, Educação Especial, Educação do Campo, Educação Indígena, Educação Profissional e Tecnológica, Educação a Distância e Educação Quilombola.
} 
EDUCAÇÃO, SAÚDE

ETECNOLOGIA

26 A 28 DE OUTUBRO DE 2021

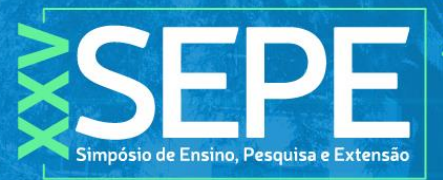

QUFN

autonomia do aluno e combater a fragmentação e transmissividade do conhecimento.

\section{CONCLUSÃO}

A pandemia da COVID-19 provocou a aceleração vertiginosa da tecnologia, que tornou-se cada vez mais indispensáveis na nossa vida. Obrigou-nos a comunicar-nos via plataformas tecnológicas, assim como, conduzir o processo educativo, também através dessas ferramentas. Todo esse processo, nos levou a rever nossas práticas educativas, repensar a forma como o processo de construção do conhecimento é conduzido e, também alguns regimes de verdade que a muito tempo estavam cristalizados.

Dessa forma, discutir sobre a docência no ensino superior, sobretudo em tempos pandêmicos, onde faz-se necessário repensar as metodologias, os processos de ensino e aprendizagem, é de suma importância, pois é na no ensino superior que os sujeitos são formados para atuarem nas diferentes realidades das quais estão inseridos.

Portanto, toda essa discussão requer uma mudança de paradigmas, uma reflexão profunda sobre a docência no ensino superior, de forma a fazer as conexões entre a teoria que é ensinada na universidade, com a prática dos diferentes espaços ocupados pelos egressos dos cursos superiores. Nessa esteira que os professores que trabalham no ensino superior precisam trabalhar com a inovação, ou seja, romper com a fragmentação do conhecimento, proporcionando aos alunos a construção do conhecimento, deslocando o foco do processo unicamente centrado no docente, para a autonomia do aluno, onde este seja protagonista do seu próprio conhecimento, e a partir das problematizações e discussões propostas, esse conhecimento possa fazer sentido e ter uma relação muito estreita com a prática quotidiana.

Isso requer do professor uma constante formação continuada, aperfeiçoamento e, principalmente uma profunda mudança de postura, para que o ensino na 
universidade venha responder às inquietações dos alunos e os leve a uma prática coerente com a realidade em que vivemos.

\section{REFERÊNCIAS}

ALMEIDA, F. Q.; GOMES, I. M., et al. Bauman \& a Educação. Coleção Pensadores \& Educação. Belo Horizonte: Autêntica Editora, 2009.

BRASIL. Ministério da Educação. Gabinete do Ministro. Portaria n. 343, de 17 de marco de 2020. Dispõe sobre a substituição de aulas presenciais por aulas em meios digitais enquanto durar a situação de pandemia do Novo Coronavírus -

COVID-19. Diário Oficial da União, ed. 53, seção 1, Brasília, DF, p. 39, 18 mar. 2020c. Disponível em http://www.in.gov.br/en/web/dou/-/portaria-n-343-de-17-demarco-de-2020-248564376. Acesso em: 2 de agosto de 2021.

CHIZZOTTI, A. A pesquisa em ciências humanas e sociais. 2. Ed - Sâo Paulo: Cortez. 2018.

GIL, A.C. Como elaborar projetos de pesquisa. 4.ed. São Paulo: Atlas, 2002.

GUSSO, H. L.; ARCHER, A. B.; LUIZ, F. B, et al. Ensino superior em tempos de pandemia: diretrizes à gestão universitária. Educação e Sociedade, Campinas, v.41, e 238957, 25 set. 2020. Disponível em: https://www.scielo.br/j/es/a/pBY83877ZkLxLM84gtk4r3f/?lang=pt. Acesso em: 12 de julho de 2021.

LIMA, V. M. R. ; GRILLO, M. C. Por que o professor faz o que faz na sala de aula? In: LIMA, V. M. R. (Org.). A gestão da aula universitária na PUCRS. Edipurs: Porto Alegre, 2008.

LUCARELLI, Elisa. El asesor pedagógico em la universidad. De la teoria pedagógica a la práctica en la formación. Buenos Aires: Paidos, 2000

MASETTO, M. Inovação no ensino superior. São Paulo: Edições Loyola, 2012.

TARDIFF, M. Saberes docentes e formação profissional. 17.ed. - Petrópolis, RJ: Vozes, 2014. 
EDUCAÇÃO, SAÚDE

ETECNOLOGIA

26 A 28 DE OUTUBRO DE 2021 